\title{
Respiratory muscle sequelae in young university students infected by coronavirus disease 2019: an observational study
}

\author{
Marta de la Plaza ${ }^{1}$ (D) Guillermo García Pérez de Sevilla ${ }^{1 *}$
}

\begin{abstract}
SUMMARY
BACKGROUND: The infection caused by coronavirus disease 2019 can lead to respiratory sequelae in individuals who have experienced severe or mild symptoms.

METHODS: An observational, cross-sectional study was developed, following the STROBE guidelines. Maximal inspiratory and expiratory mouth pressures were assessed in 50 healthy young students ( 26 women, 24 men; age $22.20 \pm 2.41$ years). The inclusion criteria were as follows: aged between 18 and 35 years; control group: not diagnosed with coronavirus disease 2019; and coronavirus disease 2019 group: diagnosed with coronavirus disease 2019, at least 6 months ago. The exclusion criteria were as follows: obese/overweight; infected with coronavirus disease 2019 or coronavirus disease 2019 symptoms in the last 6 months; smokers; and asthmatics.

RESULTS: When comparing with groups, the coronavirus disease 2019 group presented statistically significant lower maximal inspiratory pressure values compared with the control group ( $88.32 \pm 16.62$ vs. $101.01 \pm 17.42 \mathrm{~cm} \mathrm{H}_{2} \mathrm{O} ; \mathrm{p}=0.01$ ). Regarding the maximal expiratory pressure, no significant differences were found. Similar results were found when performing a subgroup analysis by sex and group.

CONCLUSIONS: Young students who suffered from coronavirus disease 2019 asymptomatically or mildly at least 6 months ago presented a significant decrease in the inspiratory muscle strength as a sequel, so we believe that patients affected by this disease should have a brief postinfection assessment of this musculature to detect the indication for cardiorespiratory rehabilitation.

KEYWORDS: COVID-19. SARS-CoV-2. Students. Complications. Respiratory muscle.
\end{abstract}

\section{INTRODUCTION}

The coronavirus disease 2019 (COVID-19) pandemic, along with pending massive and effective vaccination globally, is challenging socioeconomic, health, and political systems. The virus enters the respiratory epithelium through the receptor for angiotensin-converting enzyme 2 (ACE2), causing respiratory infection and the well-known acute respiratory syndrome due to coronavirus disease $\left(\right.$ Sars-CoV-2) ${ }^{1}$.

Sars-CoV-2 consists of an acute and sudden respiratory infection of variable course with fever, cough, dyspnea, anosmia, ageusia, muscle aches, diarrhea, chest pain, or headaches ${ }^{2,3}$.

In $80 \%$ of cases, the symptoms are mild, while $14 \%$ present more severe forms with dyspnea, hypoxia, and pneumonia and 5\% require admission to intensive care units (ICUs) with respiratory failure and multiorgan failure ${ }^{4}$. Comorbidities, such as obesity, hypertension, chronic obstructive pulmonary disease (COPD), or heart failure, increase mortality. Also, advanced age is the most relevant risk factor for the severity of the illness 5 .

Between 40 and $45 \%$ of young population do not present symptoms $s^{6}$. Also, mortality associated with ages between 20 and 49 years is relatively low, which is around $0.0092 \%{ }^{7}$. Even so, healthy young population without associated comorbidities are affected by COVID-19. Studies notify a possible genetic predisposition of these individuals ${ }^{8}$.

The infection caused by COVID-19 can lead to respiratory sequelae, but not only in those individuals who have experienced severe forms. It seems increasingly clear that the sequelae are not related to the initial severity of the disease, and although patients who are treated in long-term intensive units suffer from post-ICU syndrome, many young people with mild initial involvement develop sequelae that last for weeks and even months?

The sequelae of COVID-19 widely vary, and their manifestations fluctuate between peaks of improvement and clinical worsening. COVID-19 is a multisystemic disease, so its sequelae are very diverse. Lopez-Leon et al. reported that $80 \%$ of people who have suffered from COVID-19 present persistent symptoms ${ }^{7}$.

In a study carried out in Paris where symptoms were evaluated after an average of 111 days post-COVID-19 infection, the most prevalent symptoms were fatigue (55\% of cases), headache (44\%), dyspnea (42\%), memory loss (34\%), concentration and sleep disorders (28\%), and hair loss $(20 \%)^{10}$.

Respiratory sequelae of COVID-19 infection are very common, and the most prevalent symptoms are pulmonary

\footnotetext{
${ }^{1}$ Universidad Europea de Madrid, Faculty of Sports Sciences, Department of Physiotherapy - Madrid, Spain.

*Corresponding author: guillermo.garcia@universidadeuropea.es

Conflicts of interest: the authors declare there is no conflicts of interest. Funding: none.

Received on October 19, 2021. Accepted on November 24, 2021.
} 
dysfunction (54\% of cases), pleural thickening (27\%), polypnea $(21 \%)$, pain in the chest $(16 \%)$, and pleural effusion $(5 \%)$. The published data on persistent dyspnea are quite different, with the prevalence of being $8-43 \%$ at $4-8$ weeks and $14 \%$ at 12 weeks ${ }^{11}$.

Most of the data available so far suggest that $10-20 \%$ of patients affected by COVID-19 present symptoms 4 weeks after diagnosis. A study carried out in a sample of more than 4,000 people reported persistent symptoms in $13.3 \%$ of cases at 4 weeks, $4.5 \%$ at 8 weeks, and $2.3 \%$ at 12 weeks ${ }^{12}$.

Regarding the sequelae described in the young population, the most prevalent symptoms are dyspnea on exertion and physical deconditioning. In this line, Crameri et al. published that VO2max had decreased by $>10 \%$ in $19 \%$ of the 199 military personnel included in the study 45 days after COVID-19 diagnosis ${ }^{13}$. In another sample of 100 participants aged 45-53 years, regardless of the degree of severity of the infection, $60 \%$ of population had myocardial involvement and thus dyspnea on exertion ${ }^{14}$.

Maximal inspiratory pressure (MIP) and maximal expiratory pressure (MEP) are adequate variables to assess respiratory function. MIP is the pressure generated during maximal inspiratory effort against a closed system. The MEP is measured during a similar maneuver with the total lung capacity ${ }^{15}$.

COVID-19 patients who were admitted to ICUs and were assisted by mechanical ventilation later presented general and respiratory hypotonia ${ }^{16}$. However, concerning asymptomatic patients or with mild COVID-19 symptoms, no studies that report respiratory muscle dysfunction are available to date. Due to this reason, and due to the need to establish scientific evidence regarding this new disease, this study aims to assess respiratory muscle function in young patients who have been infected by COVID-19 in a mild or asymptomatic way.

\section{METHODS}

\section{Study design}

An observational, cross-sectional study was developed, following the STROBE guidelines from March to April 2021 at the Universidad Europea de Madrid.

\section{Settings and participants}

A total of 50 healthy young students were recruited at the Universidad Europea de Madrid (26 women, 24 men; age $22.20 \pm 2.41$ years, height $172.01 \pm 7.47 \mathrm{~cm}$, body mass $64.12 \pm 8.57 \mathrm{~kg}$ ). Participants were recruited via email between February and March 2021. They were reassured that nonparticipation had no consequences. A code was assigned to participants before statistical analysis, thus guaranteeing the confidentiality of their data.

The inclusion criteria were as follows: (1) being a student at the Universidad Europea de Madrid; (2) aged between 18 and 35 years; (3) control group (CG): not diagnosed with COVID-19; and (4) COVID-19 group (COVID-G): diagnosed with COVID-19, with a positive polymerase chain reaction (PCR) test, at least 6 months ago.

The exclusion criteria were as follows: (1) obese or overweight; (2) infected with COVID-19 in the last 6 months; (3) smokers; (4) asthmatics; and (5) experienced COVID-19 symptoms in the last 6 months.

\section{Ethical considerations}

The current study respected the Declaration of Helsinki ethical statements throughout the study. All the participants read and signed the informed consent form before being part of this investigation.

\section{Measurements}

Maximal inspiratory and expiratory mouth pressures (MIP/ MEP) were assessed using the Micro Respiratory Pressure Meter (FS985; Micro Medical, Los Angeles, CA, USA). These variables were measured in 25 subjects diagnosed with COVID-19 at least 6 months ago with mild symptoms or asymptomatic, and the same procedure was performed on 25 subjects who had not been ever diagnosed with COVID-19 or had experienced its symptoms.

The Sociedad Española de Neumología y Cirugía Torácica (SEPAR) 2003 procedures manual was followed. The participants rested for $5 \mathrm{~min}$ before performing the first maneuver. Then, they performed the maneuvers in a sitting position with a stuffy nose through a clamp that prevented air leaks and a straight back. The examiner showed the maneuver before its performance.

Participants started with MEP: an inspiration was requested at the maximum inspiratory volume with $1 \mathrm{~s}$ in inspiratory apnea and then exhaled as hard as possible. The participants rested for $1 \mathrm{~min}$ and then repeated the maneuver six times.

Next, MIP was performed. The participants were asked to exhale until the lung was empty, held for $1 \mathrm{~s}$ on maximum exhalation, and inhaled as hard as possible. They rested for $1 \mathrm{~min}$ between maneuvers until the six maneuvers recommended by the SEPAR were performed.

We recorded the highest value of the MIP and the highest value of the MEP, expressed in centimeter of $\mathrm{H}_{2} \mathrm{O}$.

Regarding anthropometric variables, height (cm; Ano Sayol SL height rod, Barcelona, Spain) and weight (kg; Asimed T2 
scale, Barcelona, Spain) were measured. Then, by dividing the weight in kilogram by the height in meters squared, the body mass index $\left(\mathrm{BMI}\right.$, in $\left.\mathrm{kg} / \mathrm{m}^{2}\right)$ was calculated.

\section{Statistical analysis}

A descriptive analysis was developed for all the subjects using mean \pm standard deviation $(\mathrm{SD})$ to describe the continuous variables. The Shapiro-Wilk test for the normality of the sample was conducted. For nonparametric variables, the Mann-Whitney $\mathrm{U}$ test was conducted, while the independent samples t-test was employed to compare the COVID-G with the CG and to determine differences between sex and the remaining of the continuous variables (i.e., MIP, MEP, BMI, age, weight, and height). The significance level was set at alpha $<0.017$ as three comparisons were performed ${ }^{17}$. All analyses were performed using SPSS version 27.0 statistical software.

\section{RESULTS}

\section{Sociodemographic data of the sample}

In total, 50 participants (26 women and 24 men), subjects ( $n=25$ ) in the COVID-G, and subjects $(\mathrm{n}=25)$ in the CG were participated in the study. In both groups, $52 \%$ of participants were women, and $48 \%$ were men. The mean age of the COVID-G was $23.11 \pm 2.67$ years, the body weight was $67.42 \pm 8.77 \mathrm{~kg}$, the height was $174.03 \pm 8.07 \mathrm{~cm}$, and the BMI was $22.21 \pm 1.50 \mathrm{~kg} /$ $\mathrm{m}^{2}$. The mean age of the CG was $21.32 \pm 1.75$ years, the weight was $60.80 \pm 7.08 \mathrm{~kg}$, the height was $170.04 \pm 6.24 \mathrm{~cm}$, and the BMI was $21.13 \pm 1.48 \mathrm{~kg} / \mathrm{m}^{2}$. In all these variables, there were significant differences between the two groups, with age, height, weight, and BMI being higher in the COVID-G compared with the CG.

\section{Maximal inspiratory and expiratory mouth pressures}

When comparing by groups, the COVID-G presented statistically significant lower values in the MIP, compared with the CG (88.32 \pm 16.62 vs. $101.01 \pm 17.42 \mathrm{~cm} \mathrm{H}_{2} \mathrm{O} ; \mathrm{p}=0.01$ ). Regarding the MEP, no significant differences were found between the COVID-G and the CG $(105.02 \pm 20.41$ vs. $103.01 \pm 15.83 \mathrm{~cm}$ $\mathrm{H}_{2} \mathrm{O} ; \mathrm{p}=0.64$ ) (Table 1).

When comparing women by group, there were no statistically significant differences in age, height, weight, and BMI between the COVID-G and the CG. MIP values were lower, with a significant difference, in the COVID-G compared with the CG (75.21 \pm 11.60 vs. $\left.88.72 \pm 10.61 \mathrm{~cm} \mathrm{H}_{2} \mathrm{O} ; \mathrm{p}<0.01\right)$. Regarding the MEP, no significant differences were found (91.81 \pm 20.10 vs. $92.30 \pm 11.23 \mathrm{~cm} \mathrm{H}_{2} \mathrm{O} ; \mathrm{p}=0.94$ ) (Table 1).
Table 1. Subgroup analysis of the maximal inspiratory and expiratory pressures.

\begin{tabular}{l|c|c|c} 
Variables & COVID vs. CG & $\begin{array}{c}\text { Women: } \\
\text { COVID-G vs. CG }\end{array}$ & $\begin{array}{c}\text { Men: COVID-G } \\
\text { vs. CG }\end{array}$ \\
$\begin{array}{l}\text { MIP } \\
\left(\mathrm{cm} \mathrm{H}_{2} \mathrm{O}\right)\end{array}$ & $\begin{array}{c}88.32 \pm 16.62 \\
\text { vs. } \\
101.01 \pm 17.42^{*}\end{array}$ & $\begin{array}{c}75.21 \pm 11.60 \\
\text { Vs. }\end{array}$ & $\begin{array}{c}103.12 \pm 5.45 \\
\text { vs. } \\
114.03 \pm 13.60^{*}\end{array}$ \\
\hline $\begin{array}{l}\text { MEP } \\
\left(\mathrm{cm} \mathrm{H}_{2} \mathrm{O}\right)\end{array}$ & $\begin{array}{c}105.02 \pm 20.41 \\
\text { vs. }\end{array}$ & $\begin{array}{c}91.81 \pm 20.10 \\
\text { vs. }\end{array}$ & $\begin{array}{c}120.01 \pm 4.42 \\
\text { vs. }\end{array}$ \\
\hline
\end{tabular}

MIP: maximal inspiratory pressure; MEP: maximal expiratory pressure; COVID-G: COVID-19 group; CG: control group. *Significance was set at $p<0.017$.

When comparing men by group, the COVID-G had a higher height, weight, BMI, and age than the CG, with a statistically significant difference between the variables. MIP values were lower, with a significant difference, in the COVID-G compared with the CG (103.12 \pm 5.45 vs. $114.03 \pm 13.60 \mathrm{~cm} \mathrm{H}_{2} \mathrm{O}$; $\mathrm{p}=0.016)$. No significant differences were found in the MEP (120.01 \pm 4.42 vs. $114.03 \pm 11.61 \mathrm{~cm} \mathrm{H}_{2} \mathrm{O} ; \mathrm{p}=0.13$ ) (Table1).

\section{DISCUSSION}

In this study, the respiratory muscle strength was analyzed in young university students who had COVID-19 mildly or asymptomatically at least 6 months ago. Significantly lower MIP values were observed in the COVID-G compared with the CG, but no significant differences were found in the MEP values.

The COVID-G had significantly higher age, weight, height, and $\mathrm{BMI}$ values. Therefore, according to the predictive equations $^{18,19}$, the COVID-G should have presented higher MIP and MEP values. As it was not the case, it may be that the COVID-19 infection caused an impairment in the strength of the inspiratory muscles. Nevertheless, in a recent systematic review about predictive MIP and MEP mouth equations, they conclude that there is high heterogeneity in these equations, and none is reliable enough ${ }^{20}$.

Comparing by groups and sex, the women of the COVID-G presented lower MIP values than those of the CG, with a statistically significant difference, without finding differences in the MEP. There were no significant differences between the women in both groups in terms of anthropometric variables. Probably, COVID-19 infection caused an impairment in the strength of the inspiratory muscles. Likewise, the men of the COVID-G presented lower MIP values than those of the CG, with a statistically significant difference, despite having a higher weight, age, height, and BMI. No differences were found regarding MEP values. 
In patients with respiratory disease, a difference of $7-13 \mathrm{~cm}$ $\mathrm{H}_{2} \mathrm{O}$ in MIP value is considered clinically significant ${ }^{21}$. In our case, although the population of our study is healthy, the COVID-G subjects presented a similar difference in MIP (being $-13.51 \mathrm{~cm} \mathrm{H}_{2} \mathrm{O}$ in the case of women, or $-15 \%$; and $-10.91 \mathrm{~cm} \mathrm{H}_{2} \mathrm{O}$ in the case of men, or $-9.5 \%$ ).

The principal sequelae of COVID-19 infection in the young population described in the literature are $\mathrm{VO} 2 \mathrm{max}$ decrease $(19 \% \text { of cases })^{13}$ and myocardial inflammation ( $60 \%$ of cases $)^{14}$. These clinical situations are not correlated with the initial severity of the infection. In our study population, young people between the ages of 18 and 35 years, who had suffered from COVID-19 asymptomatically or mildly at least 6 months ago, presented a clinically significant decrease in inspiratory force ${ }^{21}$, a fact that can be related to myocarditis or physical deconditioning, due to the relationship between MIP and VO2 $\max ^{22}$.

Since $40-45 \%$ of young people affected by SARS-CoV-2 do not present symptoms $s^{6}$, and the mortality associated with ages between 20 and 49 years is low, around $0.0092 \%$, this population tends to relax barrier measures, has little fear of contagion, and postinfection monitoring is not usually performed. However, the data from this study suggest that young people who have been infected by COVID-19 should undergo an assessment of MIP and MEP, and in case of affectation, they should carry out specific respiratory rehabilitation.

\section{Study limitations and future lines}

As a limitation of this study, we could not compare the MIP and MEP values of our population with other reference values

\section{REFERENCES}

1. Chen N, Zhou M, Dong X, Qu J, Gong F, Han Y, et al. Epidemiological and clinical characteristics of 99 cases of 2019 novel coronavirus pneumonia in Wuhan, China: a descriptive study. Lancet. 2020;395(10223):507-13. https://doi.org/10.1016/S01406736(20)30211-7

2. Richardson ET. Pandemicity, COVID-19 and the limits of public health 'science'. BMJ Glob Heal. 2020;5(4):e002571. https://doi. org/10.1136/bmjgh-2020-002571

3. Docherty AB, Harrison EM, Green CA, Hardwick HE, Pius R, Norman L, et al. Features of 20133 UK patients in hospital with covid-19 using the ISARIC WHO Clinical Characterisation Protocol: prospective observational cohort study. BMJ. 2020;369:m1985. https://doi.org/10.1136/bmj.m1985

4. Wiersinga WJ, Rhodes A, Cheng AC, Peacock SJ, Prescott HC. Pathophysiology, transmission, diagnosis, and treatment of coronavirus disease 2019 (COVID-19): a review. JAMA. 2020;324(8):782-93. https://doi.org/10.1001/jama.2020.12839

5. Guan WJ, Ni ZY, Hu Y, Liang WH, Ou CQ, He JX, et al. Clinical characteristics of coronavirus disease 2019 in China. N Engl J Med. 2020;382(18):1708-20.https://doi.org/10.1056/NEJMoa2002032 using predictive equations, since there are currently none with sufficient reliability ${ }^{20}$.

\section{CONCLUSIONS}

Although the population of this study is young and experienced an infection by COVID-19 asymptomatically or mildly at least 6 months ago, we found a significant decrease in the inspiratory muscle strength as a sequel. All the patients affected by this disease should have a brief postinfection assessment of this musculature to detect the indication for cardio-respiratory rehabilitation and describe possible sequelae of Sars-Cov-2.

\section{ETHICAL CONSIDERATIONS}

The current study was approved by the Research Ethics Committee of Universidad Europea de Madrid and respected the Declaration of Helsinki ethical statements throughout the study. All the participants read and signed the informed consent form before participating in this investigation.

\section{AUTHORS' CONTRIBUTIONS}

GGPS: Investigation, Methodology, Formal Analysis, writing - original draft. MPSF: Data curation, Investigation, Project administration, Methodology. All authors actively contributed to the discussion of the results in the study and reviewed and approved the final version to be released.

6. He J, Guo Y, Mao R, Zhang J. Proportion of asymptomatic coronavirus disease 2019: a systematic review and meta-analysis. J Med Virol. 2021;93(2):820-30. https://doi.org/10.1002/jmv.26326

7. Lopez-Leon S, Wegman-Ostrosky T, Perelman C, Sepulveda R, Rebolledo PA, Cuapio A, et al. More than 50 long-term effects of COVID-19: a systematic review and meta-analysis. Sci Rep. 2021;11:16144. https://doi.org/10.1038/s41598-021-95565-8

8. Kuo CL, Pilling LC, Atkins JL, Masoli JAH, Delgado J, Kuchel GA, et al. ApoE e4e4 genotype and mortality with COVID-19 in UK Biobank. J Gerontol Ser A Biol Sci Med Sci. 2020;75(9):1801-3. https://doi.org/10.1093/gerona/glaa169

9. Sivan M, Halpin S, Hollingworth L, Snook N, Hickman K, Clifton IJ. Development of an integrated rehabilitation pathway for individuals recovering from COVID-19 in the community. J Rehabil Med. 2020;52(8):jrm00089. https://doi.org/10.2340/16501977-2727

10. Garrigues E, Janvier P, Kherabi Y, Le BotA, Hamon A, Gouze H, etal. Post-discharge persistent symptoms and health-related quality of life after hospitalization for COVID-19. J Infect. 2020;81(6):e4-6. https://doi.org/10.1016/j.jinf.2020.08.029

11. MoX, Jian W, Su Z, Chen M, Peng H, Peng P, et al. Abnormal pulmonary function in COVID-19 patients at time of hospital discharge. Eur Respir J. 2020;55(6):2001217.https://doi.org/10.1183/13993003.01217-2020 
12. Sudre CH, Lee KA, Lochlainn MN, Varsavsky T, Murray B, Graham MS, et al. Symptom clusters in COVID-19: a potential clinical prediction tool from the COVID Symptom Study app. Sci Adv. 2021;7(12):eabd4177. https://doi.org/10.1126/sciadv.abd4177

13. Crameri GAG, Bielecki M, Züst R, Buehrer TW, Stanga Z, Deuel JW. Reduced maximal aerobic capacity after COVID-19 in young adult recruits, Switzerland, May 2020. EuroSurveill. 2020;25(36):2001542. https://doi.org/10.2807/1560-7917.ES.2020.25.36.2001542

14. Puntmann VO, Carerj ML, Wieters I, Fahim M, Arendt C, Hoffmann $J$, et al. Outcomes of cardiovascular magnetic resonance imaging in patients recently recovered from coronavirus disease 2019 (COVID-19). JAMA Cardiol. 2020;5(11):1265-73. https://doi. org/10.1001/jamacardio.2020.3557

15. Sibila O, Molina-molina M, Valenzuela C, Ríos-Cortés A, ArbillagaEtxarri A, García YT, et al. Consensus document of the Spanish Society of Pulmonology and Thoracic Surgery (SEPAR) for postCOVID-19 clinical follow-up. Open Respir Arch. 2020;2(4):278-83. https://doi.org/10.1016/j.opresp.2020.09.002

16. Abodonya AM, Abdelbasset WK, Awad EA, Elalfy IE, Salem HA, Elsayed SH. Inspiratory muscle training for recovered COVID-19 patients after weaning from mechanical ventilation: a pilot control clinical study. Medicine (Baltimore). 2021;100(13):e25339. https:// doi.org/10.1097/MD.0000000000025339
17. Lee S, Lee DK. What is the proper way to apply the multiple comparison test? Korean J Anesthesiol. 2018;71(5):353-60. https://doi.org/10.4097/KJA.D.18.00242

18. Morales P, Sanchis J, Cordero PJ, Díez JL. Maximumstatic respiratory pressures in adults. The reference values for a Mediterranean Caucasian population. Arch Bronconeumol. 1997;33(5):213-9. https://doi.org/10.1016/s0300-2896(15)30609-8

19. Enright PL,Adams AB, Boyle PJ, Sherrill DL. Spirometry and maximal respiratory pressure references from healthy Minnesota 65- to 85-year-old women and men. Chest. 1995;108(3):663-9. https:// doi.org/10.1378/chest.108.3.663

20. Souto-MirandaS, Jácome C, Alves A, Machado A, Paixão C, Oliveira $A$, et al. Predictive equations of maximum respiratory mouth pressures: a systematic review. Pulmonology. 2021;27(3):219-39. https://doi.org/10.1016/j.pulmoe.2020.03.003

21. Adaos C, González A, Slater D, Medina P, Muñoz R, Escobar M. Análisis de presión inspiratoria máxima según tres protocolos en estudiantes voluntarios asintomáticos de la Universidad Católica del Maule, Chile. Rev Chil Enferm Respir. 2017;33(1):21-30. https://doi.org/10.4067/s071773482017000100004

22. Hackett DA. Lung function and respiratory muscle adaptations of endurance- and strength-trained males. Sports. 2020;8(12):160. https://doi.org/10.3390/sports8120160 